\title{
Inmovilización de lactobacillus helveticus en soportes vítreos obtenidos por tecnología sol-gel
}

\author{
J. F. BETANCUR, Y. B. RESTREPO, P. ABAD, M. ARIAS \\ Universidad Nacional de Colombia Sede Medellín, Facultad de Ciencias A.A. 3840 Medellín Colombia
}

\begin{abstract}
La inmovilización de biocatalizadores tales como células y enzimas, es una herramienta utilizada en el mejoramiento de procesos biotecnológicos que permite trabajar con concentraciones más altas del biocatalizador retenido dentro del bio-reactor, y evitar su pérdida en la corriente efluente. Así; entre otras ventajas, se facilita operar en forma continua reduciendo el número de operaciones de separación y por lo tanto, el costo de purificación del producto. Para tal fin, inicialmente se estudia la factibilidad técnica de inmovilizar células de lactobacillus helveticus por atrapamiento en soportes vítreos elaborados mediante tecnología sol-gel, utilizando como precursor tetraetil-orto-silicato (TEOS). Posteriormente, se determina la viabilidad de las células inmovilizadas a través de su capacidad de convertir en ácido láctico la lactosa proveniente del suero de leche.

Éstos resultados se compararon con los obtenidos utilizando células libres bajo las mismas condiciones de operación, y se observó que las células inmovilizadas además de conservar su actividad metabólica, en algunos casos mejoraron la conversión a ácido láctico. Se obtuvieron partículas estables con distribución de tamaño de 1 a $3 \mathrm{~mm}$, buena resistencia mecánica y un tamaño de poro que no resultó altamente restrictivo a la transferencia de moléculas entre sustrato y producto. Finalmente, se determinó que las células inmovilizadas mostraban buen comportamiento durante al menos cinco fermentaciones sucesivas de 40 horas cada una.
\end{abstract}

Palabras clave: sol gel, lactobacillus helveticus, inmovilización biocatalizadores.

Inmobilisation of lactobacillus helveticus using vitreous monoliths from sol - gel technology

The immobilization of bio catalyst agents like cells and enzymes, is a tool used to improve and simplify biotechnical continued industrial processes, given that it allows to work with higher concentrations of the bio catalyst agent, retain it inside the bioreactor to avoid their loss in the outside current, decreases the number of separation operations, and therefore, the cost of purification of the product. For such an end, we studied the technical feasibility of immobilizing cells of lactobacillus helveticus encapsulating it in supports elaborated by means of Sol-Gel process using as precursor tetraetil-orto-silicate (TEOS) and later, with immobilized cells, we studied the viability of the cells through its capacity of conversion of the lactose coming from the serum of milk in lactic acid.

These results were compared with those obtained using free cells under the same operation conditions, and it was observed that the immobilized cells didn't only conserve their metabolic activity, but rather, in some cases, the conversion of lactose to lactic acid was improved. Obtained particles had size distribution among $1-3 \mathrm{~mm}$, good mechanical resistance, stability in the support, and a pore size that it was not highly restrictive to the transfer of molecules between support and product. Finally, the immobilized cells showed good behaviour during at least five successive fermentations of 40 hours each one.

Keywords: Sol-gel, lactobacillus helveticus, inmobilization

\section{INTRODUCCIÓN}

La inmovilización de células y enzimas presenta como ventajas poder operar en forma continua y trabajar con concentraciones más altas del biocatalizador, para su aplicación industrial requiere desarrollar técnicas de retención en el bioreactor fácilmente escalables. En el presente trabajo se estudia la factibilidad de atrapar el biocatalizador en un gel que sin alterar su función catalítica, lo proteja de contaminación y de efectos inhibitorios de elementos presentes en el seno del medio.

En general, los portadores pueden ser membranas, partículas o capas del gel, a partir de materiales que incluyen alginato, carraginato, triacetato de celulosa, poliacrilamida, colágeno, gelatina, agar, resinas, poliéster y poliuretano. Con ellos se puede atrapar por encapsulación, microencapsulación o por colonias cubiertas [1-3]. Dado que en el atrapamiento se puede limitar la transferencia de masa, comúnmente se prefieren muchas esferas pequeñas que permitan al sustrato llegar hasta la célula en todas las direcciones, incrementando el área de contacto entre la biomasa y el sustrato. Teniendo en cuenta que muchos agentes utilizados en la elaboración del soporte pueden resultar tóxicos para la célula, se ha preferido el uso de polímeros naturales que como desventaja presentan una baja estabilidad química y mecánica.

En la tecnología sol-gel, una suspensión o sol es llevada a un estado de gel mediante la síntesis química de óxidos, permitiendo la obtención de gran variedad de materiales en forma de fibras, películas delgadas, polvos o monolitos. Una característica fundamental de esta tecnología que la hace apta para ser usada en inmovilización celular, es el hecho de poderse realizar a temperaturas aceptables para el metabolismo 
celular. En diferentes estudios sobre la inmovilización de especies biológicas por atropamiento dentro de una matriz vítrea por sol-gel [4-8], se ha demostrado que las biomoléculas atrapadas en matrices de este tipo mantienen la mayoría de sus características, adquiriendo mayor resistencia a la temperatura y más estabilidad. En particular, se ha demostrado que el sacaromices cerevisiae inmovilizado en películas sol-gel conserva su actividad. Es de anotar que la integración de células durante el procesamiento se debe ajustar, según las restricciones concernientes, a la manipulación de sistemas vivos.

Dada la importancia de la inmovilización celular aplicable en el campo industrial, en el presente trabajo se investigó la factibilidad de obtener, mediante tecnología sol-gel, un material particulado con estructura apropiada para la inmovilización de células de lactobacillus helveticus desarrollada en condiciones aptas para que la célula conserve su actividad metabólica.

\section{PROCEDIMIENTO.}

\subsection{Elaboración del soporte.}

Para su elaboración se empleó el procedimiento de hidrólisis en dos etapas, utilizando como precursor tetraetil-orto-silicato (TEOS) y como reactivos agua destilada, etanol absoluto, ácido clorhídrico e hidróxido de amonio ambos en concentración $0.1 \mathrm{M}$, que además de servir como catalizadores, permiten ajustar el pH inicial de la solución. Para la matriz o soporte de inmovilización, se buscó un monolito que posteriormente se fragmentara hasta formar partículas de tamaños distribuidos principalmente entre 1 y $3 \mathrm{~mm}$, esto es, dimensiones superiores al tamaño de la colonia de L. Helveticus entre 1 y $2 \mathrm{~mm}$ y con una porosidad inferior a la dimensión micrométrica de la célula. Con el fin de obtener las características deseadas y explorando intervalos que respeten las restricciones del sistema vivo, se realizaron tres series de experimentos en los cuales se varió la relación molar de dos de los componentes de la mezcla, manteniendo las otras relaciones constantes.

En una primera serie, considerando que para la conservación de la célula el valor del pH finalmente debía estar entre 6 y 7 , se estudió la influencia del pH en el tamaño de partícula. Para tal fin se varió progresivamente la relación molar amoníaco/TEOS, desde 0 hasta 0.003, manteniendo constante la relación molar de los otros componentes en los valores: TEOS/agua, TEOS/etanol y TEOS/ $\mathrm{HCl}$ de 1/8, 1/3,1/3.6x10${ }^{4}$, respectivamente (Tabla 1 ).

Como condiciones adecuadas para la elaboración del soporte, se escogieron aquellas que produjeron un monolito que tras la inmersión en el medio agitado en una Macrocentrífuga Indulab 08-T, produjera el mayor porcentaje de partículas entre mallas 8 y 10 (2.38 mm y $1.68 \mathrm{~mm}$, respectivamente). Estas condiciones correspondieron a valores de $\mathrm{pH}$ entre 6 y 7 que afortunadamente son propicios para el metabolismo del lactobacillus helveticus.

En la segunda serie se varió la relación molar agua/TEOS progresivamente desde 6 hasta 16, controlando la relación molar amoníaco/TEOS para mantener el pH entre 6 y 7. Es así como las demás relaciones para componentes de la mezcla se mantuvieron en los valores de relación molar TEOS/etanol y TEOS $/ \mathrm{HCl}$ de $1 / 3,1 / 3.6 \times 10^{-4}$, respectivamente (Tabla 1 ).

Explorando el mínimo contenido posible de etanol por su acción nociva sobre la célula, en la tercera serie de experimentos se varió la relación molar etanol/TEOS desde 0 hasta 2 , manteniendo el $\mathrm{pH}$ en el intervalo deseado y conservando constantes las relaciones de los otros componentes en los valores de relación molar TEOS/agua y TEOS/ $\mathrm{HCl}$ de 1/10, $1 / 3.6 \times 10^{-4}$, respectivamente (Tabla 1). Estos resultados se compararon respecto a otras pruebas realizadas con altas concentraciones de etanol.

TABla 1. Pruebas Con VARIACiÓn de las RElaciones AMONÍACO/TEOS, AGUA/TEOS Y ETANOL/TEOS

\begin{tabular}{|c|c|c|c|c|c|}
\hline Muestra & $\begin{array}{c}\text { Relación } \\
\text { Amoníaco/TEOS }\end{array}$ & Muestra & $\begin{array}{c}\text { Relación } \\
\text { agua/TEOS }\end{array}$ & Muestra & $\begin{array}{c}\text { Relación } \\
\text { etanol/TEOS }\end{array}$ \\
\hline 1 & 0.003 & 7 & 6 & 13 & 2.0 \\
\hline 2 & 0.002 & 8 & 8 & 14 & 1.5 \\
\hline 3 & 0.001 & 9 & 10 & 15 & 1.0 \\
\hline 4 & 0.0006 & 10 & 12 & 16 & 0.5 \\
\hline 5 & 0.0003 & 11 & 14 & 17 & 0.0 \\
\hline 6 & 0 & 12 & 16 & & \\
\hline
\end{tabular}

\subsection{Inmovilización celular}

Una vez verificadas la resistencia mecánica bajo condiciones de agitación propias del reactor y la estabilidad en condiciones de fermentación de los monolitos obtenidos, se procedió a inmovilizar en ellos células de lactobacillus helveticus a partir de una cepa liofilizada suministrado por CHR.HANSEN. Para ello se realizaron varios experimentos encaminados a determinar el mejor momento de adición de las células durante la formación del monolito, buscando no sólo la inmovilización, sino la conservación de su viabilidad.

Teniendo en cuenta que el etanol a altas concentraciones puede resultar inhibitorio, se hizo necesario verificar si en el intervalo definido las células permanecían vivas. Se estudiaron varias relaciones molares etanol/TEOS para diferentes concentraciones de biomasa en la solución, controlando que los monolitos conservaran las características adecuadas previamente establecidas.

La cantidad de amoníaco empleada fue la necesaria para mantener el $\mathrm{pH}$ entre 6 y 7 . Para relaciones molares etanol/ TEOS de 0,$5 ; 1,0$ y 1,5 respectivamente, se observó el efecto de las variaciones del porcentaje volumétrico de la suspensión de células en el sol inmovilizante, ensayando valores de la relación molar biomasa/TEOS entre 2 y 16. Las relaciones probadas se hicieron con relación molar constante de los demás componentes de la mezcla: TEOS/agua y TEOS / $\mathrm{HCl}$ de 1/10 y $1 / 3.6 \times 10^{-4}$, respectivamente.

Finalmente, para la integración de la célula, el primer paso es la formación de un sol parcialmente hidrolizado; el segundo, involucra la adición de la especie biológica en una solución reguladora a la solución para obtener el gel, ajustándose el pH próximo a la neutralidad para evitar la desnaturalización de la especie biológica o la destrucción de la célula entera. Esta matriz dopada se agita vigorosamente alcanzando la gelificación en 1-2 minutos y se seca durante dos semanas para obtener un monolito con el biocatalizador atrapado, luego se lava varias veces con la solución reguladora y agua destilada, para su uso final (Figura 1). 


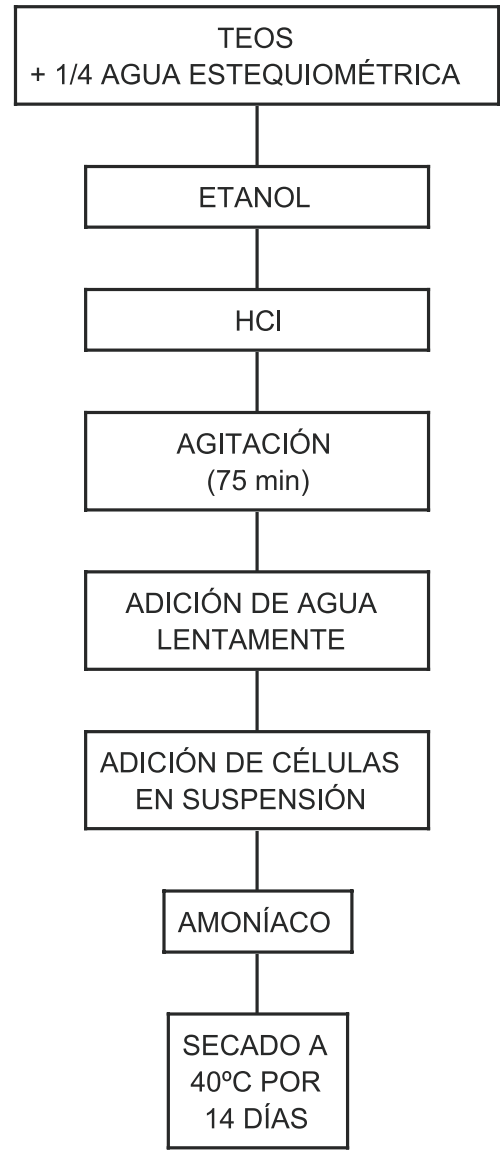

Figura 1. Preparación del gel e inmovilización celular

\subsection{Estudio de viabilidad de las células inmovilizadas.}

Una vez establecidas las condiciones para inmovilizar células de lactobacillus helveticus en un material particulado, se procedió a determinar si, una vez inmovilizadas, las células conservan su actividad metabólica y, en particular, su capacidad de convertir la lactosa en ácido láctico. Para tal fin, bajo las mismas condiciones de temperatura, $\mathrm{pH}$, concentración de inóculo, concentración de sustrato y agitación del medio, se realizaron fermentaciones simultáneas de lactosuero con células inmovilizadas y células libres en suspensión. Las fermentaciones se efectuaron en lactosuero suplementado con extracto de levadura a $43^{\circ} \mathrm{C}$, agitado en un agitador rotatorio durante $40 \mathrm{~h}$. Previendo un contenido de células no inmovilizadas, antes de la fermentación se hizo un lavado del soporte para removerlas. La valoración del producto se hizo en el espectrofotómetro de adsorción Spectronic 20 Genesis.

\section{RESULTADOS.}

\subsection{Elaboración del soporte.}

Se observó que a $\mathrm{pH}$ próximo a la neutralidad la hidrólisis y la condensación ocurrían lentamente, dando como resultado una estructura más resistente a la fractura. Luego, al sumergir los monolitos obtenidos en lactosuero sometido a la agitación mecánica, se escogieron aquellas pruebas que luego de la in- mersión dieron un alto porcentaje de partículas en las mallas 8 y 10 que corresponden a 2,38 mm y 1,68 mm respectivamente, capaces de inmovilizar las colonias de lactobacillus helveticus con tamaños entre 1 y 2 mm. Así mismo, se observó que el material particulado tomaba un color amarillento, similar al del lactosuero, indicando la penetración del medio en los poros de las partículas.

En la segunda serie se observó claramente que el uso de cantidades de agua elevadas resulta en un detrimento de la calidad del monolito para efectos de inmovilización celular. Esto se explica por la dilución de las cadenas monoméricas, dificultando su interacción y posterior crecimiento hacia una macroestructura tipo gel [9]. Después del secado, las estructuras monodispersas se compactaron y dieron paso a la formación de polvos.

Con valores de relación molar agua/TEOS de 8 y 10, respectivamente, siempre se obtuvieron monolitos con propiedades adecuadas, por lo que se escogió el valor de 10 para un menor porcentaje de etanol dentro de la solución, en razón de su efecto inhibitorio a concentraciones altas.

A bajas relaciones molares etanol/TEOS o en ausencia de etanol, durante el proceso de secado siempre se produjo la fragmentación del monolito en partículas de tamaño más o menos uniformes, resistentes cuando eran sumergidas en el lactosuero. Para las pruebas realizadas con altas concentraciones de etanol, las partículas se desintegraban durante la inmersión. De acuerdo con Brinker[9] y Sglavo y col.[8], esto puede deberse a que el disolvente que activa las cadenas poliméricas no fue el suficiente para propiciar la polimerización que conduciría a un monolito compacto.

Se partió siempre de soluciones homogéneas y transparentes que conservaron su transparencia durante la gelificación. De los resultados obtenidos se estableció que la relación molar agua/TEOS igual a 10, pH entre 6 y 7, así como relaciones molares etanol/TEOS inferiores a 2, son condiciones ajustadas para obtener partículas de tamaño aproximadamente homogéneo en el intervalo de 1 a $3 \mathrm{~mm}$, con características adecuadas para la inmovilización celular. Igualmente se determinó que el secado durante 14 días a $40^{\circ} \mathrm{C}$ daba como resultado un xerogel estable. El material obtenido mostró un comportamiento positivo ante las evaluaciones de su resistencia mecánica en condiciones de agitación, propias de un proceso de fermentación, y de su estabilidad en dicho medio (lactosuero).

3.2 Inmovilización celular

Se halló que la adición a la solución inicial de la especie biológica en una solución reguladora para obtener el gel, conducía a los mejores resultados. El pH de la solución inmovilizante; después de agregado el inóculo, fue similar al de la solución sin células, indicando que la suspensión no tenía una influencia marcada en la acidez del medio.

La formación de la estructura polimérica del soporte se vio afectada de manera positiva por la presencia de la célula que, según lo observado, sirvió como puente entre el precursor y el agua haciendo que el tiempo de gelificación fuese menor. Además, la presencia de la suspensión con la célula le confirió resistencia a la estructura e hizo que los tamaños de partícula obtenidos fuesen mayores. Las tres concentraciones bajas de alcohol dieron buenos resultados, observándose que a menor relación se requieren tiempos de agitación más prolongados y una adición lenta del agua. Un buen resultado se obtuvo para relaciones molares etanol $/$ TEOS $=1$, biomasa $/$ TEOS $=3$ con un tiempo de agitación de 3 horas. 
3.3 Estudio de viabilidad de las células inmovilizadas.

La valoración del producto se hizo con un espectrofotómetro de adsorción Spectronic 20 Genesis. El estudio de fermentaciones con células libres e inmovilizadas se realizó para valores de la relación molar etanol/TEOS iguales a 1 y 1,5. Los resultados comparativos se observan en los gráficos de barras de las figuras 2 y 3 respectivamente.

Con un comportamiento similar y sin una variación significativa en la producción de ácido láctico, para las dos relaciones molares etanol/TEOS se observa que hasta un valor de concentración de biomasa dada por la relación volumen inóculo / volumen suero de 0,014, se tuvo una producción de ácido láctico mayor con las células inmovilizadas. A partir de ésta concentración, el comportamiento se invierte haciéndose mayor la producción con las células libres. Este cambio puede ser ocasionado por la presencia de compuestos orgánicos, tales como la biomasa y los nutrientes en el medio, que afectaron el proceso de polimerización incidiendo en la porosidad y, por ende, en el proceso difusivo. Además, se confirma que las concentraciones altas de biomasa perjudican la estructura del soporte. En resumen, con una relación volumen inóculo/volumen suero en el entorno de 0,014 , la cantidad de compuesto orgánico es suficiente para servir como puente durante la polimerización aumentando la estabilidad mecánica y, a su vez, la concentración de sólidos no es suficiente para afectar negativamente la estructura del soporte. Para una relación molar etanol/TEOS = 2, también ensayada, no hubo fermentación, pues a esta concentración el etanol resultó nocivo para la célula.

La importancia del uso de la inmovilización celular para fermentaciones en continuo hizo necesario evaluar el tiempo durante el cual las células permanecen activas dentro del soporte. Bajo las mismas condiciones se efectuaron fermentaciones sucesivas reemplazando el medio por lactosuero fresco cada $40 \mathrm{~h}$ y repitiendo el proceso hasta completar cinco fermentaciones. La Figura 4 muestra la concentración en gramos/litro de ácido láctico de cinco fermentaciones sucesivas con célula inmovilizada, en función de la concentración inicial de biomasa (dada por la relación volumen inóculo/volumen suero), confrontando ésta producción con la de las células libres, siempre bajo las mismas condiciones de operación.

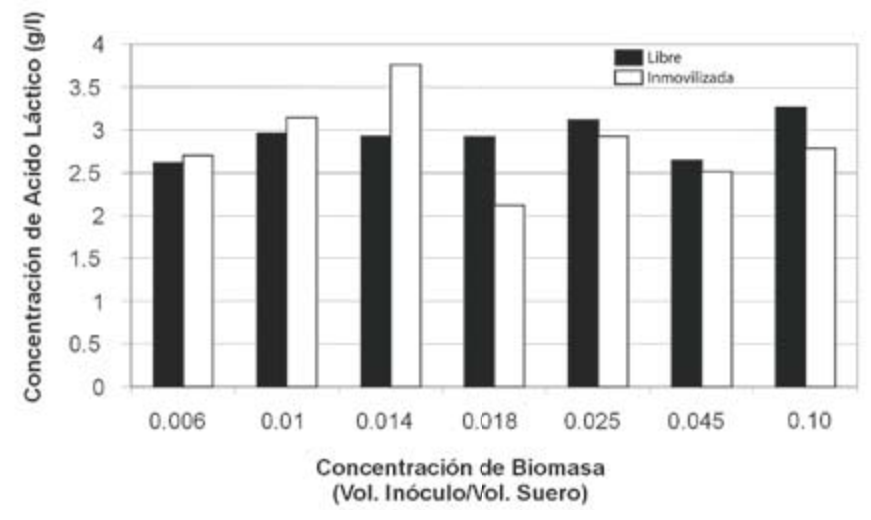

Figura 2. Producción de ácido láctico con células libres e inmovilizadas para diferentes concentraciones de biomasa y relación etanol/ TEOS $=1$

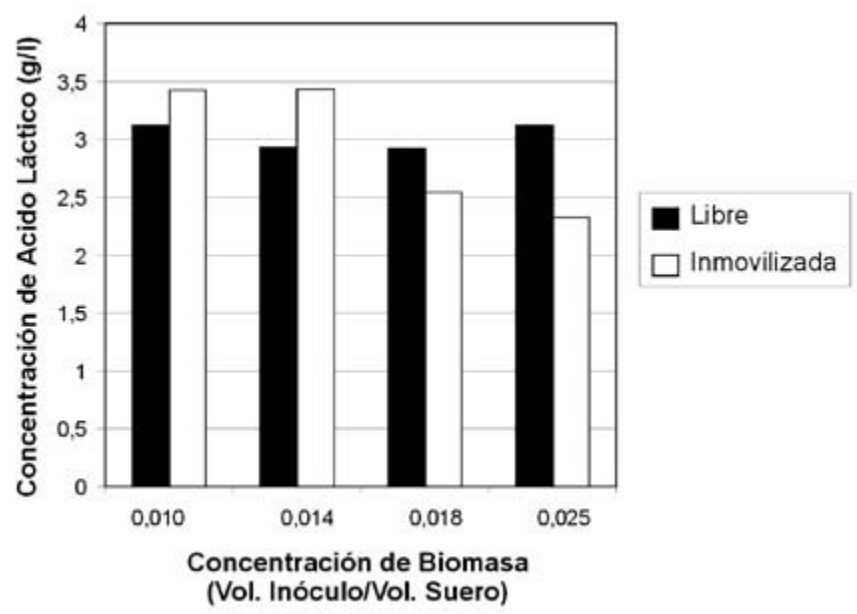

Figura 3. Producción de ácido láctico con células libres e inmovilizadas para diferentes concentraciones de biomasa y relación etanol/ TEOS $=1,5$

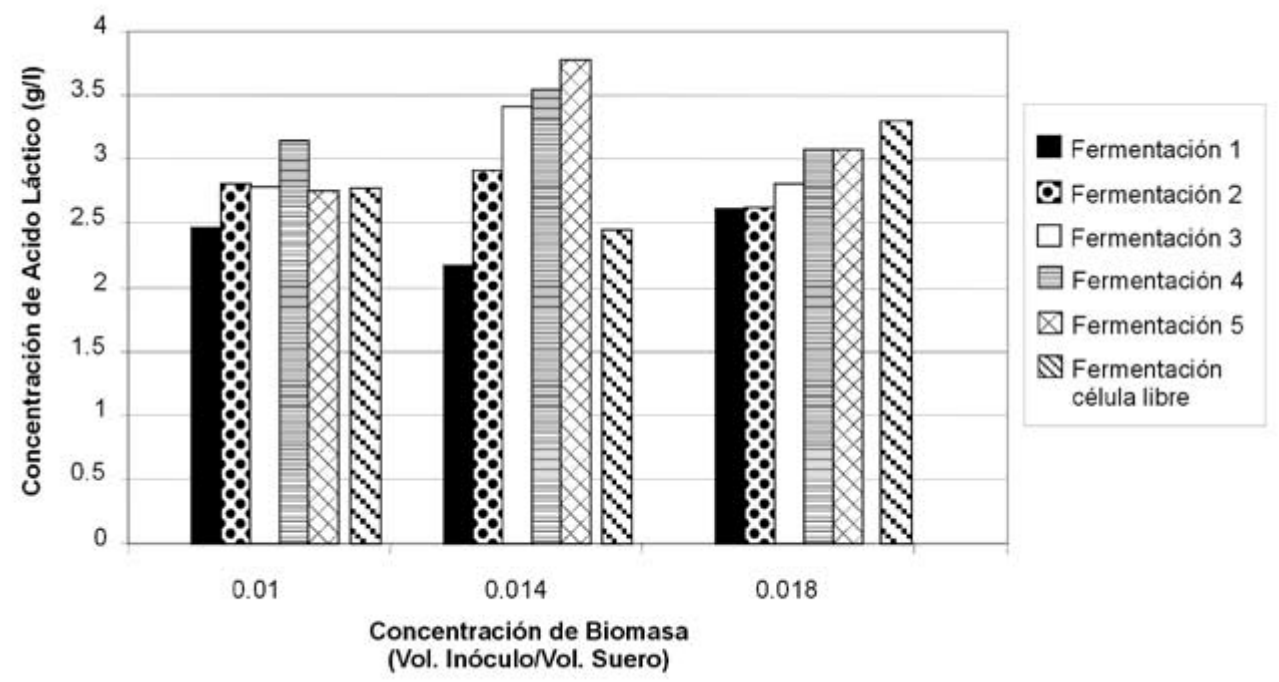

Figura 4. Concentración de ácido láctico obtenido en 5 fermentaciones sucesivas con células inmovilizadas. 
Se debe anotar que después de la primera fermentación, el soporte con la célula inmovilizada se lavó y se guardó durante quince días. En las cuatro fermentaciones sucesivas restantes y hasta una concentración inicial de biomasa que corresponde a una relación de 0,014 , se observa un perfil de aumento, siempre por encima de la concentración de ácido láctico obtenida con la célula libre. Este aumento de la actividad celular a lo largo de fermentaciones sucesivas, se puede deber a un acondicionamiento de la bacteria al medio de fermentación y a que el soporte cumplió su función como protector, al atenuar la inhibición de los microorganismos por el descenso del $\mathrm{pH}$.

Para una concentración de biomasa obtenida con una relación de 0,018, la situación se invierte y se hace mayor la concentración obtenida con células libres, confirmándose la tendencia ya observada en las figuras 2 y 3 . Para concentraciones iniciales de biomasa mayores, los resultados no presentan ninguna tendencia ni resultados similares para repeticiones del proceso. No obstante, la actividad celular se conservó: las células permanecen activas al menos durante cinco fermentaciones discontinuas de $40 \mathrm{~h}$ de duración cada una. Este resultado es mejor que el de Champagne y col. [3] donde los lactobacillus helveticusinmovilizados en alginato de calcio mantuvieron su actividad durante 7 fermentaciones de 3 horas cada una.

Así por ejemplo, para una concentración inicial de biomasa igual a 1,4 dada por la relación volumen inóculo/volumen suero, la concentración final de ácido láctico con las células inmovilizadas fue de $3,4 \mathrm{~g} / 1$ frente a $2,9 \mathrm{~g} / 1$ obtenido con células libres. Las mejores condiciones de elaboración del soporte y de inmovilización de las células fueron: relación molar agua/TEOS de 10, pH entre 6 y 7, relación molar etanol/TEOS inferior a 2, para trabajar con concentraciones de etanol por debajo del $20 \%$, temperatura de secado $40^{\circ} \mathrm{C}$ y tiempo de secado 14 días.

\section{CONCLUSIONES.}

Es posible inmovilizar células de lactobacillus helveticus en soportes elaborados mediante el procedimiento sol-gel, conservando su viabilidad celular e, inclusive, mejorando la producción de ácido láctico respecto a la obtenida con las cé- lulas libres. La producción durante fermentaciones sucesivas confirma que el soporte evita la inhibición celular, mejorando la producción.

La interacción célula - soporte fue de mutuo beneficio, pues a la vez que la célula inmovilizada resiste mejor las condiciones adversas de los procesos industriales y evita su inhibición por el producto, la presencia del lactobacillus helveticus durante la formación del monolito contribuye a la homogeneidad del sistema. La formación de la estructura polimérica del soporte se vio influenciada de manera positiva por la presencia de la célula, que según lo observado, sirvió como puente entre el precursor y el agua haciendo que el tiempo de gelación fuese menor. Además, la presencia de la célula le confirió mayor resistencia a la estructura bajo las mismas condiciones de agitación mecánica.

Cabe anotar que el monolito obtenido en esta experimentación no alcanzó a convertirse en vidrio, porque no hay proceso de sinterización. Este material es un xerogel estable.

Los resultados obtenidos en ésta primera etapa de viabilidad, permiten pasar a una segunda fase de escalamiento, calibrando métodos y técnicas de caracterización más rigurosas.

\section{BIBLIOGRAFÍA}

1. A. Groboillot, D. Poncelet. «Immobilization of Cells for Aplication in the Food Industry » Critical Reviews in Biotechnology. 14 [2] 75-107 (1994)

2. J. V. SINISTERRA. «Inmovilización de células y enzimas ». Anales de la Real Academia de Farmacia. Madrid. 59 [3] 267-300 (1993).

3. C. P. Champagne, C. Gaudy, J. Goulet. « Fermentation du lactosérum par cellules inmobiliseés de lactobacillus helveticus» J. Canadian Inst. Food Sci. Tech. 21 403- 407 (1988).

4. M . Al-Saraj,. M.S. Abdel-Latif. «Bioacumulation of some hazardous metals by Sol-Gel entrapped microorganisms. » J. Non-Cryst Solids 248 137-140 (1999).

5. L Armanini, G. Carturan, S. Boninsegna. « $\mathrm{SiO}_{2}$ entrapment of animal cells. Part 2: Protein diffusion through collagen membranes coated with Sol-Gel $\mathrm{SiO}_{2} »$ J. Mat. Chem. 9 [1] 3057-3060 (1999).

6. T. Branyik, G. Kuncova, J . Paca, K. Demnerova. «Encapsulation of microbial cells into silica gel. » J. Sol-Gel Sci. Tech. 13 283-287 (1998).

7. R. Campostrini, G. Carturan, R. Caniato. "Immobilization of plant cell in hybrid Sol-Gel materials. » J. Sol-Gel Sci. Tech. 787 - 98 (1996).

8. V. M. Sglavo, G. Carturan, R. Dal Monte, M Muraca. « $\mathrm{SiO}_{2}$ entrapment of animal cells - Part I - mechanical features of Sol-Gel $\mathrm{SiO}_{2}$ coatings. » J. Mat. Sci. 34 [15] $3587-3590$ (1999).

9. C. J. Brinker. "Hydrolisis and condensation of silicates: efects on structure. » J. Non-Cryst Solids $100 \quad 31-50$ (1988). 